\title{
Suppression of Chlorella vulgaris Growth by Cadmium, Lead, and Copper Stress and Its Restoration by Endogenous Brassinolide
}

\author{
Andrzej Bajguz
}

Received: 29 January 2010/Accepted: 17 May 2010/Published online: 4 June 2010

(C) The Author(s) 2010. This article is published with open access at Springerlink.com

\begin{abstract}
Brassinosteroids play a significant role in the amelioration of various abiotic and biotic stresses. In order to elaborate their roles in plants subjected to heavy metals stress, Chlorella vulgaris cultures treated with $10^{-8} \mathrm{M}$ brassinolide (BL) were exposed to $10^{-6}-10^{-4} \mathrm{M}$ heavy metals (cadmium, lead and copper) application. Under heavy metals stress, the growth and chemical composition (chlorophyll, monosaccharides, and protein content) have been decreased during the first $48 \mathrm{~h}$ of cultivation. The inhibitory effect of heavy metals on $C$. vulgaris cultures was arranged in the following order: copper $>$ lead $>$ cadmium. C. vulgaris cultures treated with BL in the absence or presence of heavy metals showed no differences in the endogenous level of BL. On the other hand, treatment with heavy metals results in BL level very similar to that of control cell cultures. These results suggest that the activation of brassinosteroids biosynthesis, via an increase of endogenous BL, is not essential for the growth and development of $C$. vulgaris cells in response to heavy metals stress. Simultaneously, BL enhanced the content of indole-3-acetic acid, zeatin, and abscisic acid in cultures treated with heavy metals. Levels per cell of chlorophylls, protein, and monosaccharides are all increased by BL treatment when compared to nontreated control cells. Application of BL to $C$. vulgaris cultures reduced the accumulation of heavy metals stress on growth, prevented chlorophyll, monosaccharides, and protein loss, and increased phytochelatins content. The arrested growth of $C$. vulgaris cells treated with heavy metals was restored by the coapplication of BL. It suggested that BL overcame the inhibitory
\end{abstract}

\footnotetext{
A. Bajguz $(\bowtie)$

Department of Plant Biochemistry and Toxicology, Institute of Biology, University of Bialystok, Swierkowa 20 B, 15-950 Bialystok, Poland e-mail: abajguz@uwb.edu.pl
}

effect of heavy metals. From these results, it can be concluded that BL plays the positive role in the alleviation of heavy metals stress.

Algae have attracted considerable attention for the capacity to eliminate heavy metals. However, much of the knowledge concerning algae is based in observations of higher plants. The research presented here reflects this fact but stresses important discoveries relating to microalgae-for example, the evidence of the ecological importance of algal-mediated chelating mechanisms in environments. Heavy metal pollution is one of the most important environmental problems today. Various industries produce and discharge wastes containing different heavy metals into the environment, such as mining and smelting of metalliferous, surface finishing industry, energy and fuel production, fertilizer and pesticide industry and application, metallurgy, iron and steel, electroplating, electrolysis, electro-osmosis, leatherworking, photography, electric appliance manufacturing, metal surface treating, aerospace and atomic energy installation, and so forth. The toxic effect of heavy metals on plant growth and development is commonly known. Inhibition of growth limited photosynthesis and respiration. Inhibited biosynthesis of chlorophyll and carotenoids and reduced phosphorylation are most frequently observed symptoms of metal toxicity (Poskuta et al. 1996; Prasad 2004; Smirnoff 1995).

The objective of the present study was to determine the effects of various heavy metals [cadmium $(\mathrm{Cd})$, lead $(\mathrm{Pb})$, and copper $(\mathrm{Cu})]$ together with brassinolide $(\mathrm{BL})$ on the growth and accumulation of those heavy metals by algal cells and the cellular content of phytochelatins, chlorophyll, monosaccharides, andd protein in Chlorella vulgaris. Brassinosteroids (BRs) are a group of plant hormones, which is represented by BL. They are essential for normal plant 
growth, reproduction, and development. BRs play critical roles in a variety of physiological responses in plants, including stem elongation, pollen tube growth, leaf bending and epinasty, root growth inhibition, ethylene biosynthesis, proton pump activation, vascular differentiation, nucleic acid and protein synthesis, and photosynthesis (Hayat and Ahmad 2003; Khripach et al. 1999). BRs have also been implicated in plant responses to environmental stresses, such as cold stress, water deficit, salt injury, pathogen infection, oxidative damage, thermal stress, and metal stress. Despite the correlation between abiotic stress and BR levels in plants, the physiological rationale for such alteration in BR levels is still not known (Bajguz and Hayat 2009). The effects of heavy metals mixed with BL on its endogenous level in $C$. vulgaris cells have been also studied. To my knowledge this is the first evidence that treatment with heavy metals results in a BL level very similar to that of control cell cultures.

\section{Materials and Methods}

Plant Material, Growth Conditions, and Treatment

The axenic cultures of $C$. vulgaris Beijerinck (Trebouxiophyceae) were grown under controlled conditions at $25 \pm 0.5^{\circ} \mathrm{C}$. Illumination was supplied during the 16 -h photoperiod (8-h dark period) by a bank of fluorescent lights yielding a photon flux of $50 \mu \mathrm{mol} / \mathrm{m}^{2} / \mathrm{s}$ at the surface of the tubes. Complete synchronization has been obtained by a regular change of light and dark periods according to the method of Pirson and Lorenzen (1966) under conditions developed by Sayegh and Greppin (1973). The homogenous population of young synchronous cells was collected by centrifugation $\left(2000 \mathrm{~g}, 10 \mathrm{~min}, 20^{\circ} \mathrm{C}\right)$ and used for subsequent experiments. Synchronization of the culture was controlled by studying cell division and the diagrams of cell size distribution. Experimental cell cultures were initiated at $1.6 \times 10^{6}$ cells $^{-1}$. The culture medium used was modified Knop's medium consisting of the following nutrient solution: $4.94 \times 10^{-3} \mathrm{M} \mathrm{KNO}_{3}, 2.12 \times 10^{-3} \mathrm{M} \mathrm{Ca}\left(\mathrm{NO}_{3}\right)_{2} \cdot 4 \mathrm{H}_{2} \mathrm{O}$, $1.47 \times 10^{-3} \quad \mathrm{M} \quad \mathrm{KH}_{2} \mathrm{PO}_{4}, \quad 6.09 \times 10^{-4} \mathrm{M} \quad \mathrm{MgSO}_{4}$. $7 \mathrm{H}_{2} \mathrm{O}, 3.70 \times 10^{-5} \mathrm{MFeSO}_{4} \cdot 7 \mathrm{H}_{2} \mathrm{O}, 4.85 \times 10^{-5} \mathrm{M} \mathrm{H}_{3} \mathrm{BO}_{3}$, $1.01 \times 10^{-5} \mathrm{M} \mathrm{MnCl}_{2} \cdot \mathrm{H}_{2} \mathrm{O}, 2.56 \times 10^{-6} \mathrm{M} \mathrm{NH}_{4} \mathrm{VO}_{3}$, $6.96 \times 10^{-7} \mathrm{M} \mathrm{ZnSO}_{4} \cdot 7 \mathrm{H}_{2} \mathrm{O}$, and $8.09 \times 10^{-8} \mathrm{M}\left(\mathrm{NH}_{4}\right)_{6}$ $\mathrm{Mo}_{7} \mathrm{O}_{24} \cdot 7 \mathrm{H}_{2} \mathrm{O}$. The $\mathrm{pH}$ of the medium was adjusted to 6.8 with $1 \mathrm{M} \mathrm{NaOH}$. C. vulgaris cells were cultured in Erlenmeyer flasks $(500 \mathrm{ml})$ each containing $250 \mathrm{ml}$ medium and shaken at $150 \mathrm{rpm}$ in a rotary shaker. Algal cultures were collected on the 24th, 36th, and 48th hour of cultivation.

Brassinolide was prepared as an ethanolic solution and has been added directly to culture medium $\left(10^{-8} \mathrm{M}\right.$ final concentration). Equal amount of ethanol was added to the controls. The final ethanol concentration in the culture media did not exceed $0.001 \%(\mathrm{v} / \mathrm{v})$, and this concentration did not affect the growth of algae. The amounts of sterile solution of heavy metals were also added to the algal cultures to obtain the required concentration of heavy metal in the growing solution $\left(10^{-6}-10^{-4} \mathrm{M}\right)$. Heavy metals have been added in their nitrate forms $\left[\mathrm{Cd}\left(\mathrm{NO}_{3}\right)_{2} \cdot 4 \mathrm{H}_{2} \mathrm{O}\right.$, $\mathrm{Pb}\left(\mathrm{NO}_{3}\right)_{2}, \mathrm{Cu}\left(\mathrm{NO}_{3}\right)_{2} \cdot 3 \mathrm{H}_{2} \mathrm{O}$ ] (Sigma Chemical Co., USA). The combined effects of heavy metals and BL were examined: $\mathrm{BL}$, at $10^{-8} \mathrm{M}$, combined with different concentrations of $\mathrm{Cd}, \mathrm{Pb}$, and $\mathrm{Cu}\left(10^{-6}-10^{-4} \mathrm{M}\right)$. However, the combination of $10^{-4} \mathrm{M}$ heavy metals and BL has been used to determine the endogenous content of phytohormones. In this concentration, heavy metals had the greatest inhibitory effect on the growth of $C$. vulgaris cultures.

\section{Determination of Brassinolide Content}

Determination of the endogenous BL level in the cultures of C. vulgaris was performed on extract with internal $\left[{ }^{2} \mathrm{H}_{6}\right] \mathrm{BL}$, which is widely accepted as the most accurate method of BR determination (Bajguz 2009b). Lyophilized plant materials $(50 \mathrm{~g} \times 10)$ from $C$. vulgaris cultures were extracted with $300 \mathrm{ml}$ of methanol $(\mathrm{MeOH})$-chloroform $\left(\mathrm{CHCl}_{3}\right)(4: 1)$ twice, and $\left[^{2} \mathrm{H}_{6}\right] \mathrm{BL}$ was added to the extract as the internal standard. After evaporation of the solvent in vacuo, the extract was partitioned between $\mathrm{CHCl}_{3}$ and water three times. The $\mathrm{CHCl}_{3}$-soluble fraction was subjected to silica gel chromatography (Sep-Pak Vac Silica, $35 \mathrm{ml}$; Waters, Milford, USA). The column was subsequently eluted with $100 \mathrm{ml}$ of $\mathrm{CHCl}_{3}$ and $7 \%(\mathrm{v} / \mathrm{v}) \mathrm{MeOH}$ in $\mathrm{CHCl}_{3}$. Each 7\% (v/v) MeOH fraction was purified by Sephadex LH-20 column chromatography (column volume of $200 \mathrm{ml}$ ). The column was eluted with $\mathrm{MeOH}-\mathrm{CHCl}_{3}$ (4:1). The effluents of elution volume/total column volume: $0.6-0.8$ were collected as the BL fraction. After purification on an ODS cartridge (Sep-Pak Plus $\mathrm{C}_{18}$; Waters, Milford, USA) with $20 \mathrm{ml}$ of $\mathrm{MeOH}$, eluates were subjected to ODS-HPLC (high-performance liquid chromatography) (Pak ODS, octadecyl silane $10 \times 30 \mathrm{~mm}+20 \times 250 \mathrm{~mm}$; Senshu Scientific, Japan) at a flow rate of $8 \mathrm{ml} / \mathrm{min}$ with the solvents $65 \%(\mathrm{v} / \mathrm{v})$ acetonitrile for the eluate derived from the $7 \%(\mathrm{v} / \mathrm{v})$ $\mathrm{MeOH}$ fraction. HPLC purification from the $7 \%(\mathrm{v} / \mathrm{v}) \mathrm{MeOH}$ fraction yielded a BL fraction (Rt, retention time 10-15 $\mathrm{min}$ ), and the fraction was analyzed by GC-MS (gas chromatography-mass spectrometry) after bismethaneboronation. The presence of endogenous nonlabeled BL was examined by GC-SIM, single ion monitoring-MS (JMS AX 505 W Instrument; JEOL, Japan) after derivatization.

\section{Determination of Abscisic Acid Content}

For the determination of endogenous abscisic acid (ABA) content, the algae were first collected by centrifugation 
$\left(3300 \mathrm{~g}, 15 \mathrm{~min}, 20^{\circ} \mathrm{C}\right.$ ), and then the pellets were immediately frozen in liquid $\mathrm{N}_{2}$, and then freeze-dried. The ABA content has been determined according to Bajguz (2009a).

Determination of Indole-3-Acetic Acid and Zeatin Content

Indole-3-acetic acid (IAA) and zeatin content were checked by using the enzyme immunoassay detection kit for quantitative determination of these plant hormones according to the technical protocol of Sigma (USA).

\section{Determination of Heavy Metal Content}

A Solaar M6 (Thermo Electron Corporation, UK) atomic absorption spectrometer with a deuterium background correction system was used for $\mathrm{Pb}, \mathrm{Cd}$, and $\mathrm{Cu}$ determination in the biomass of $C$. vulgaris. The absorbances of $\mathrm{Pb}, \mathrm{Cd}$, and $\mathrm{Cu}$ were measured in an air-acetylene flame with a $0.5-\mathrm{nm}$ spectral bandpass at $\lambda=217.0 \mathrm{~nm}$, $\lambda=228.8 \mathrm{~nm}$, and $\lambda=324.7 \mathrm{~nm}$, respectively. A stock solution $(0.1 \mathrm{~mol} / \mathrm{l})$ of $\mathrm{Pb}, \mathrm{Cd}$, and $\mathrm{Cu}$ were prepared by dissolving $\mathrm{Pb}\left(\mathrm{NO}_{3}\right)_{2}, \mathrm{Cd}\left(\mathrm{NO}_{3}\right)_{2} \cdot 4 \mathrm{H}_{2} \mathrm{O}$, and $\mathrm{Cu}\left(\mathrm{NO}_{3}\right)_{2}$. $3 \mathrm{H}_{2} \mathrm{O}$ in $2 \mathrm{ml}$ of $2 \mathrm{~mol} / \mathrm{l} \mathrm{HNO}_{3}$ and dilution with Milli-Q water. Standard solutions were prepared from stock solutions daily.

For metal determination in biomass, $C$. vulgaris cultures were first collected by centrifugation $\left(3300 \mathrm{~g}, 15 \mathrm{~min}, 20^{\circ} \mathrm{C}\right)$ of $25 \mathrm{ml}$ culture samples and then the algal pellets were dried at $70^{\circ} \mathrm{C}$ for $12 \mathrm{~h}$ and ashed in a muffle furnace at $500 \pm 50^{\circ} \mathrm{C}$ for $6 \mathrm{~h}$. For measurement the ash was dissolved in $2 \mathrm{ml} \mathrm{HNO}_{3}$ (65\%; Fluka). The calculated quantitation limit for $\mathrm{Cd}$ dissolved in nitric acid was LOQ $=0.027 \mathrm{mg} / \mathrm{l}$ and the detection limit was $\mathrm{LOD}=0.0018 \mathrm{mg} / \mathrm{l}$. The calculated quantitation limit for $\mathrm{Pb}$ dissolved in nitric acid was LOQ $=0.226 \mathrm{mg} / \mathrm{l}$ and the detection limit was $\mathrm{LOD}=0.062 \mathrm{mg} / \mathrm{l}$. The calculated quantitation limit for $\mathrm{Cu}$ dissolved in nitric acid was $\mathrm{LOQ}=0.215 \mathrm{mg} / \mathrm{l}$ and the detection limit was $\mathrm{LOD}=0.059 \mathrm{mg} / \mathrm{l}$.

\section{Determination of Growth}

Cell density was determined by direct counting of cells in the growth medium using a Bürker cell chamber.

Determination of Chlorophylls, Monosaccharides, and Proteins Content

For chlorophyll determination, C. vulgaris cultures were first collected by centrifugation $\left(3300 \mathrm{~g}, 15 \mathrm{~min}, 20^{\circ} \mathrm{C}\right)$ of $10 \mathrm{ml}$ culture samples and then the algal pellets were homogenized in methanol. The absorbance of the extract was measured at 653 and $666 \mathrm{~nm}$. The amounts of chlorophyll- $a+b$ present in the extract were calculated according to the equations of Wellburn (1994).

For monosaccharides determination, $C$. vulgaris cultures were first collected by centrifugation $(3300 \mathrm{~g}, 15 \mathrm{~min}$, $20^{\circ} \mathrm{C}$ ) of $10 \mathrm{ml}$ culture samples. Cellular monosaccharides content was determined using the Somogyi (1954) method.

For protein determination, $C$. vulgaris cultures were first collected by centrifugation $\left(3300 \mathrm{~g}, 15 \mathrm{~min}, 20^{\circ} \mathrm{C}\right)$ of $10 \mathrm{ml}$ culture samples and then the algal pellets were extracted overnight in $0.1 \mathrm{M} \mathrm{NaOH}$ at $4^{\circ} \mathrm{C}$. The concentration of cellular protein was determined by the method of Bradford (1976) with a protein kit calibrated with bovine serum albumin as the standard.

The absorbances were measured with a Shimadzu (Japan) UV-Vis 1201 spectrophotometer.

\section{Determination of Phytochelatins}

The total phytochelatins content was detected by the HPLC method with postcolumn reaction with Ellman's reagent according to Tukendorf and Rauser (1990). The algae were first collected by centrifugation $\left(3300 \mathrm{~g}, 15 \mathrm{~min}, 20^{\circ} \mathrm{C}\right)$ of $10-\mathrm{ml}$ culture samples and then the algal pellets were homogenized in a small mortar and pestle on ice with a quadruple volume of $0.1 \mathrm{M} \mathrm{HCl}$. Homogenates were centrifugated $\left(5000 \mathrm{~g}, 5 \mathrm{~min}, 4^{\circ} \mathrm{C}\right)$ and obtained supernatants were used for the chromatographic method.

\section{Replication and Statistical Analysis}

Each treatment consisted of four replicates and each experiment was carried out at least twice at different times. The data were analyzed by one-way analyses of variance (ANOVAs) and the means were separated using Duncan's multiple-range test (Statistica 6; StatSoft, USA). The level of significance in all comparisons was $p<0.05$.

\section{Results}

Number of C. vulgaris Cells

The most stimulating influence on the number of cells of C. vulgaris was shown by $\mathrm{BL}$ alone with respect to the control (Fig. 1). The combination of different heavy metals, in the range of concentration $10^{-6}-10^{-4} \mathrm{M}$, and BL at $10^{-8}$ $M$ showed a weaker stimulation of the number of cells compared with the control. The lowest effect was shown by $\mathrm{Cu}$ with $\mathrm{BL}$; at the same concentrations, the growth in the number of algae was $96-142 \%$, compared with the control. The data provided indicate that under the influence of $\mathrm{BL}$ mixed with heavy metals, an increase in the number of 
Fig. 1 Effect of heavy metals $(\mathrm{Cd}, \mathrm{Pb}$, and $\mathrm{Cu})$ in the absence or presence of $\mathrm{BL}$ on the growth of $C$. vulgaris expressed as a number of cells. Data are means $\pm \operatorname{SE}(n=15)$. Before treatment of $C$. vulgaris cultures, the number of cells was established at $5 \times 10^{5}$ cells/ml. Treatments with the same letter are not significantly different according to Duncan's test

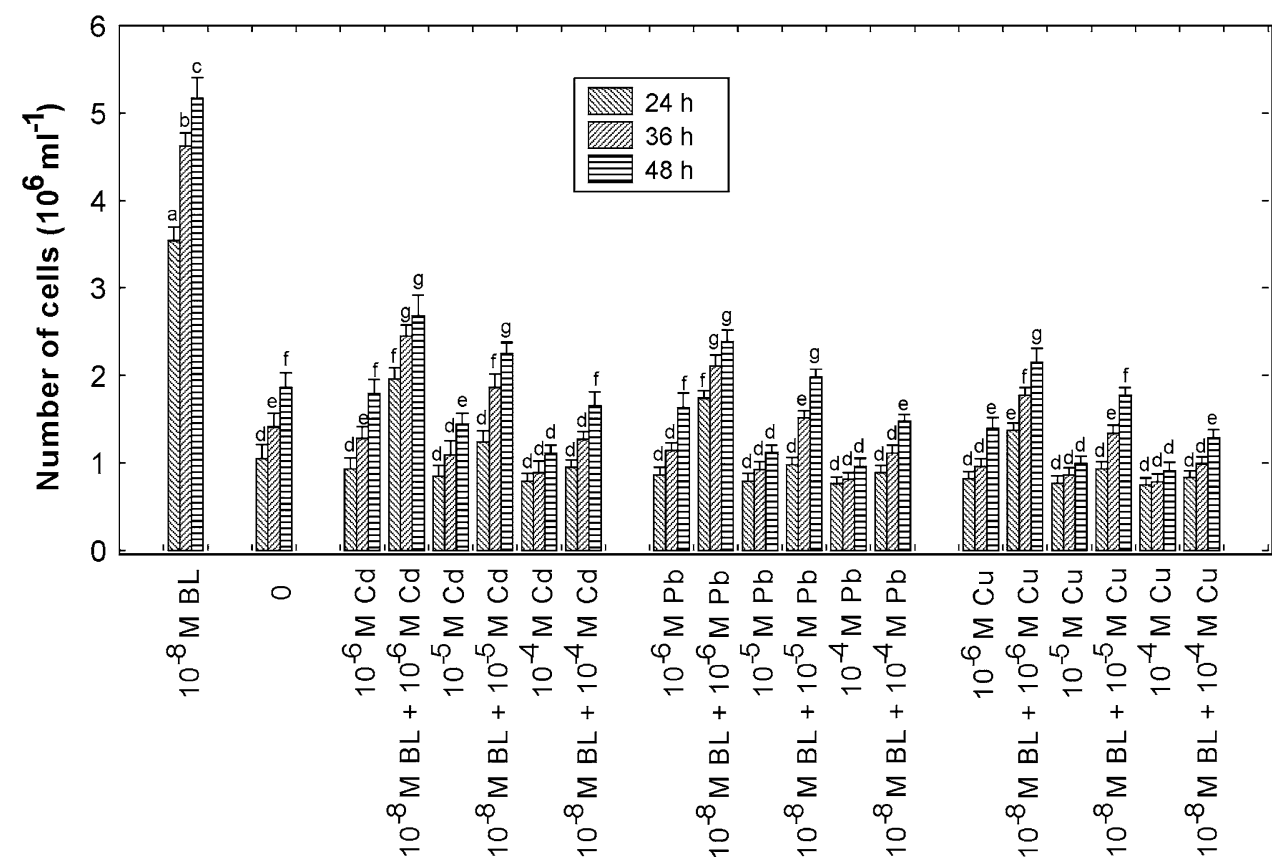

C. vulgaris cells occurs compared with the cultures exposed to the metal solely. It suggested that BL overcame the inhibitory effect of heavy metals. The stimulatory effect of BL mixed with different heavy metals on the growth of $C$. vulgaris was arranged in the following order: $\mathrm{Cd}>\mathrm{Pb}>\mathrm{Cu}$.

Heavy Metals Accumulation in C. vulgaris Cells

Chlorella vulgaris accumulated heavy metals in a doseand exposure-dependent manner (Table 1). Obtained data indicated that $\mathrm{Cu}$ in the observed concentration ranges $10^{-6}-10^{-4} \mathrm{M}$ was accumulated more effectively in comparison to the remaining heavy metals $(\mathrm{Cd}$ and $\mathrm{Pb})$. The highest accumulation of metal ions was observed in algae exposed to $10^{-4} \mathrm{M} \mathrm{Cu}$. The addition of BL to the growth medium decreased significantly all of the metals accumulation by the cells. C. vulgaris treated with $10^{-8} \mathrm{M} \mathrm{BL}$ and heavy metals (in the range of concentrations $10^{-6}-10^{-4} \mathrm{M}$ ) demonstrated the inhibition of their accumulation. At the highest concentration of metal $\left(10^{-4} \mathrm{M}\right)$ plus BL there was the highest reduction of accumulation. The content of heavy metals in $C$. vulgaris cells was proportional to the concentration of metal ions in the culture. These results suggest that BL blocked the accumulation of heavy metals in C. vulgaris. The inhibitory effect of BL mixed with different heavy metals on their accumulation was arranged in the following order: $\mathrm{Cd}>\mathrm{Pb}>\mathrm{Cu}$.

\section{Phytohormones Content in C. vulgaris Cells}

In this experiment, heavy metals stress treatment also significantly increased ABA, IAA, and zeatin contents compared to control cultures (Fig. 2). In the normal growth conditions (without metals treatment), endogenous BL showed an increase of the ABA, IAA, and zeatin contents compared to the control. The present work demonstrates that BL significant enhanced the content of IAA, zeatin, and $\mathrm{ABA}$ in $C$. vulgaris treated with heavy metals. In contrast to these results, the endogenous content of BL in C. vulgaris cells was not affected by heavy metals treatment. Heavy-metals-treated C. vulgaris cells result in BL levels very similar to that of control cell cultures. The application of a mixture of $10^{-8} \mathrm{M} \mathrm{BL}$ and heavy metals to C. vulgaris culture resulted in an increase in the level of $\mathrm{BL}$ compared to untreated cells. However, this mixture of compounds does not show an increase on the endogenous BL level in C. vulgaris, which was similar to that observed in cells treated with BL alone.

\section{Chlorophyll Content in C. vulgaris Cells}

Chlorella vulgaris cultures treated with heavy metals $\left(10^{-6}-10^{-4} \mathrm{M}\right)$ displayed chlorosis because a significant loss in total chlorophyll content was observed between the 24th and 48th hour of cultivation (Fig. 3). Heavy metals had the greatest inhibitory effect at a concentration of $10^{-4}$ M. In contrast, at a concentration of $10^{-6} \mathrm{M}, \mathrm{Cd}$ had a similar effect on the chlorophyll content in $C$. vulgaris cells compared to the control culture. The reduction of chlorophyll content in $C$. vulgaris cells treated with these metals has been prevented by the coapplication of $10^{-8} \mathrm{M}$ BL. The combination of BL and heavy metals showed a stimulating influence on the content of chlorophyll in the cells of $C$. vulgaris, without regard to their concentrations or the 


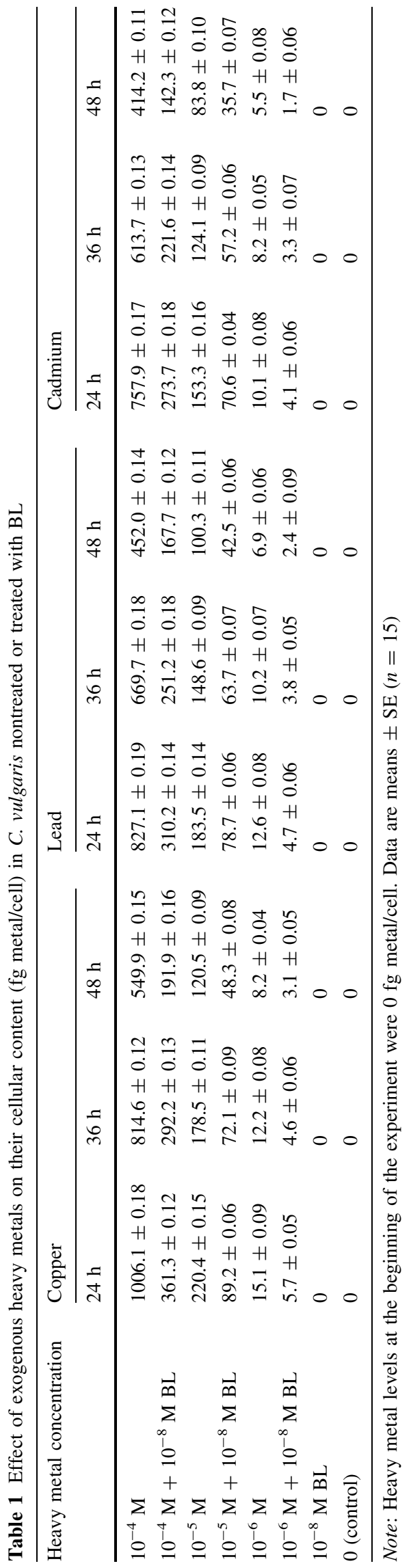

period of the cultivation. The cultures treated with $\mathrm{BL}$ and $10^{-6} \mathrm{M}$ heavy metals show a lower increase on the content of chlorophyll than the cultures treated with BL alone.

\section{Monosaccharides Content in C. vulgaris Cells}

Heavy metals were characterized by an inhibitory influence on the monosaccharides content in a concentrationdependent manner (Fig. 4). Therefore, the significant decrease in the level of monosaccharides has been obtained under the highest concentration of $10^{-4} \mathrm{M}$ for all heavy metals. The inhibitory effect of heavy metals on the monosaccharides content was also arranged in the following order: $\mathrm{Cd}=\mathrm{Pb}>\mathrm{Cu}$. The inhibitory effect of heavy metals on the content of monosaccharides in C. vulgaris cells was suppressed by the coapplication of BL. The combination of $10^{-6} \mathrm{M}$ heavy metals and $10^{-8} \mathrm{M}$ $\mathrm{BL}$ appeared to have the highest stimulatory effect on the monosaccharides content after $48 \mathrm{~h}$ of cultivation compared to the control. However, this mixture of compounds showed a stimulatory effect, which was lower than that observed in cells treated with $\mathrm{BL}$ alone. A decrease in heavy metals concentration caused an increase in monosaccharides content in $C$. vulgaris cells, especially with the interaction of BL.

\section{Protein Content in C. vulgaris Cells}

The protein content in C. vulgaris cells decreased proportionally with the increase in heavy metals concentration at all exposure periods, except for $24 \mathrm{~h}$, and the maximum decline in this biochemical parameter was under the influence of $10^{-4} \mathrm{M}$ heavy metals between the 24th and 48th hour of cultivation (Fig. 5). The lowest activity in decreasing protein content has been demonstrated at a concentration of $10^{-5} \mathrm{M}$. The inhibitory effect of heavy metals on the protein content in $C$. vulgaris cells was also suppressed by the coapplication of BL.

\section{Phytochelatins Content in C. vulgaris Cells}

Chlorella vulgaris cultures treated with heavy metals alone showed a weaker increase of total phytochelatins (PCs) content (Fig. 6a) between the 6th and the 12th hour of cultivation than the culture treated with BL and heavy metals. The stimulating effect of heavy metals alone on PCs content was observed from the 12th to 48th hour and peaked at the 36th hour. The highest increase of PCs content in heavy-metals-treated $C$. vulgaris cells was exerted at a concentration of $10^{-4} \mathrm{M}$ and the weakest was exerted at $10^{-6} \mathrm{M}$.

Brassinolide together with heavy metals increased the growth, which was correlated with an increase of total PCs 
Fig. 2 Effect of heavy metals $(\mathrm{Cd}, \mathrm{Pb}$, and $\mathrm{Cu})$ in the absence or presence of $\mathrm{BL}$ on the endogenous content of phytohormones in C. vulgaris cultures for the 48-hr treatment. Data are means $\pm \operatorname{SE}(n=15)$. Treatments with the same letter are not significantly different according to Duncan's test

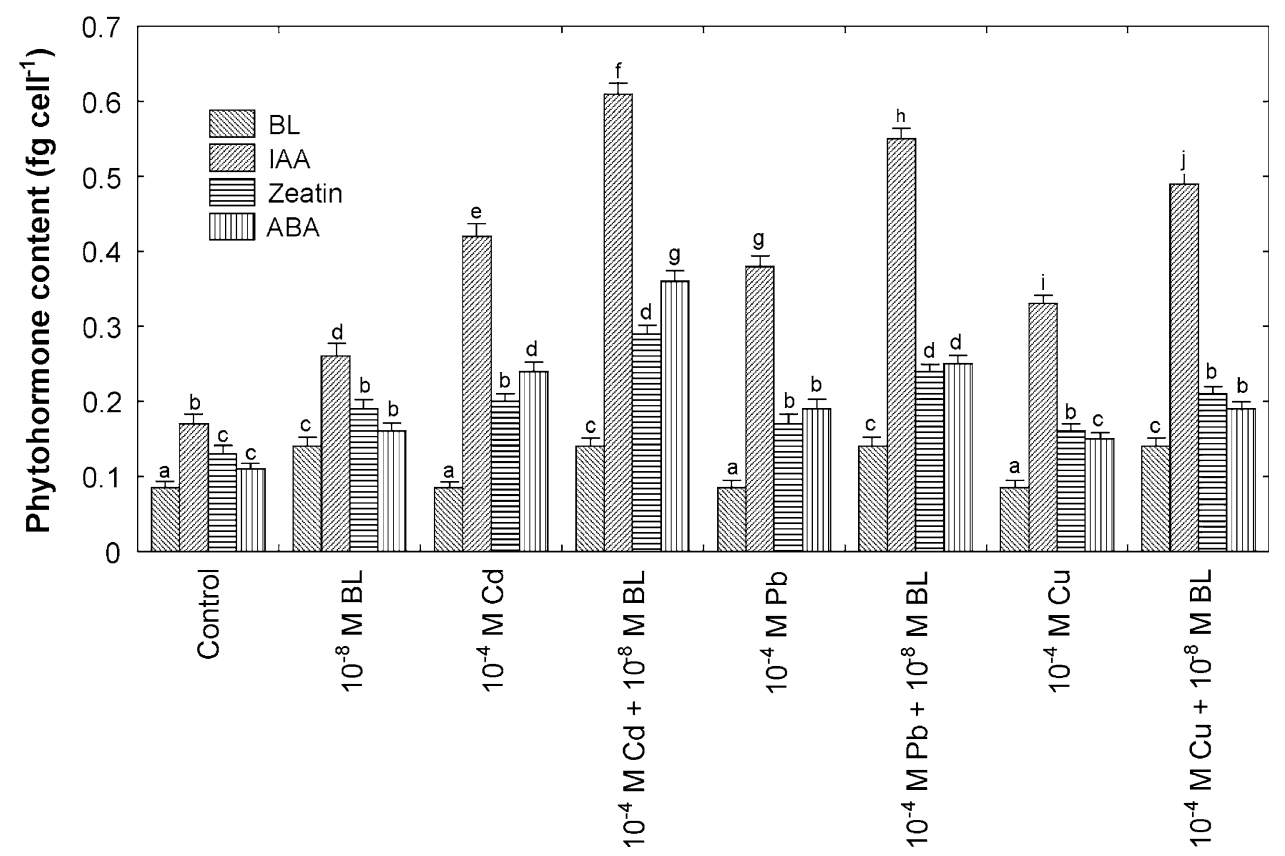

Fig. 3 Effect of heavy metals $(\mathrm{Cd}, \mathrm{Pb}$, and $\mathrm{Cu})$ in the absence or presence of $\mathrm{BL}$ on the total chlorophyll content in C. vulgaris cultures. Data are means \pm SE $(n=15)$. Before treatment of $C$. vulgaris cultures, the chlorophyll content was established at $3.5 \mathrm{fg} / \mathrm{cell}$. Treatments with the same letter are not significantly different according to Duncan's test

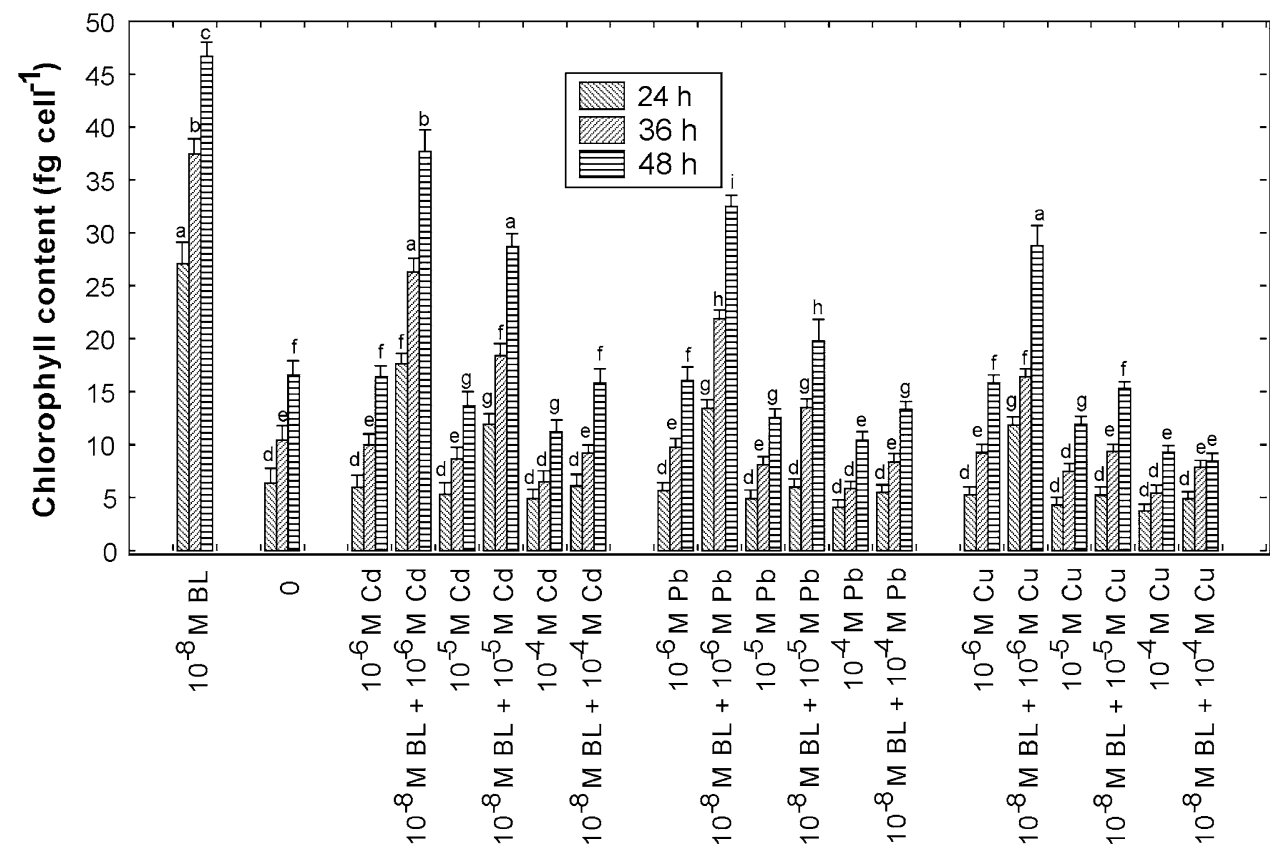

content (not shown). The maximal PCs value was increased with the highest heavy metals concentrations. The most stimulating effect on PCs content was shown by $10^{-8} \mathrm{M}$ BL with $10^{-4} \mathrm{M}$ heavy metals (Fig. 6b).

\section{Discussion}

Obtained results indicated that the biosorption of heavy metals by $C$. vulgaris is accompanied by an induction of a variety of biochemical changes, some of which directly contribute to metal tolerance capacity of the plant. Many studies on heavy-metals-polluted waters have revealed that metal pollution decreases algal diversity and productivity and alters algal species composition. However, there are also many reports concerning the occurrence of several algal (Fahmi et al. 1982; Foster 1982; Gupta and Chandra 1994; Harding and Whitton 1976; Takamura et al. 1989) and cyanobacterial species (Vymazal 1990), which are tolerant or resistant to $\mathrm{Cd}, \mathrm{Cu}, \mathrm{Pb}$, or zinc $(\mathrm{Zn})$. Algae are able to eliminate metal ions from aquatic solutions in a short time by biosorption in uncomplicated systems, 

$(\mathrm{Cd}, \mathrm{Pb}$, and $\mathrm{Cu})$ in the absence or presence of $\mathrm{BL}$ on the monosaccharides content in C. vulgaris cultures. Data are means $\pm \operatorname{SE}(n=15)$. Before treatment of $C$. vulgaris cultures, the sugar content was established at $19 \mathrm{fg} / \mathrm{cell}$.

Treatments with the same letter are not significantly different according to Duncan's test
Fig. 4 Effect of heavy metals

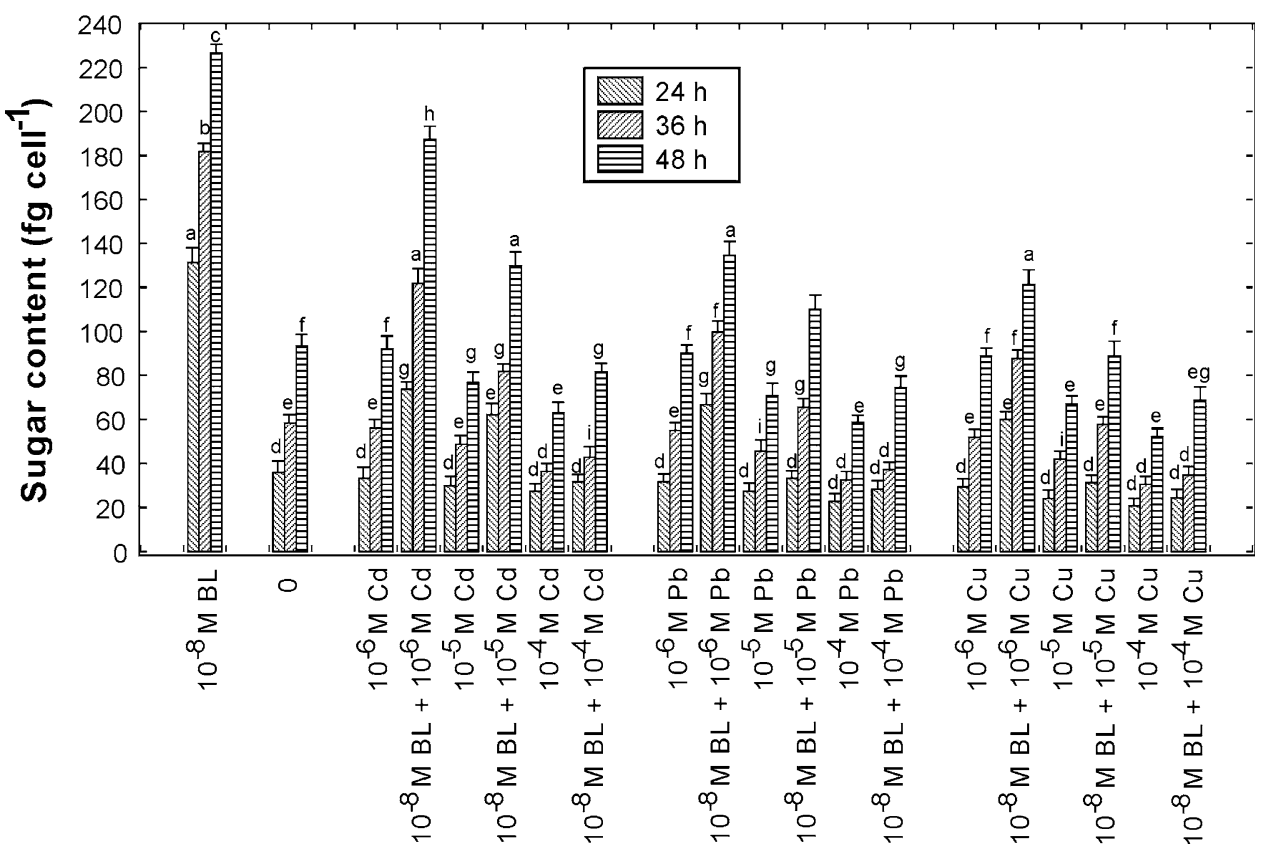

Fig. 5 Effect of heavy metals $(\mathrm{Cd}, \mathrm{Pb}$, and $\mathrm{Cu})$ in the absence or presence of $\mathrm{BL}$ on the protein content in $C$. vulgaris cultures. Data are means \pm SE $(n=15)$. Before treatment of $C$. vulgaris cultures, the protein content was established at $25 \mathrm{fg} / \mathrm{cell}$.

Treatments with the same letter are not significantly different according to Duncan's test

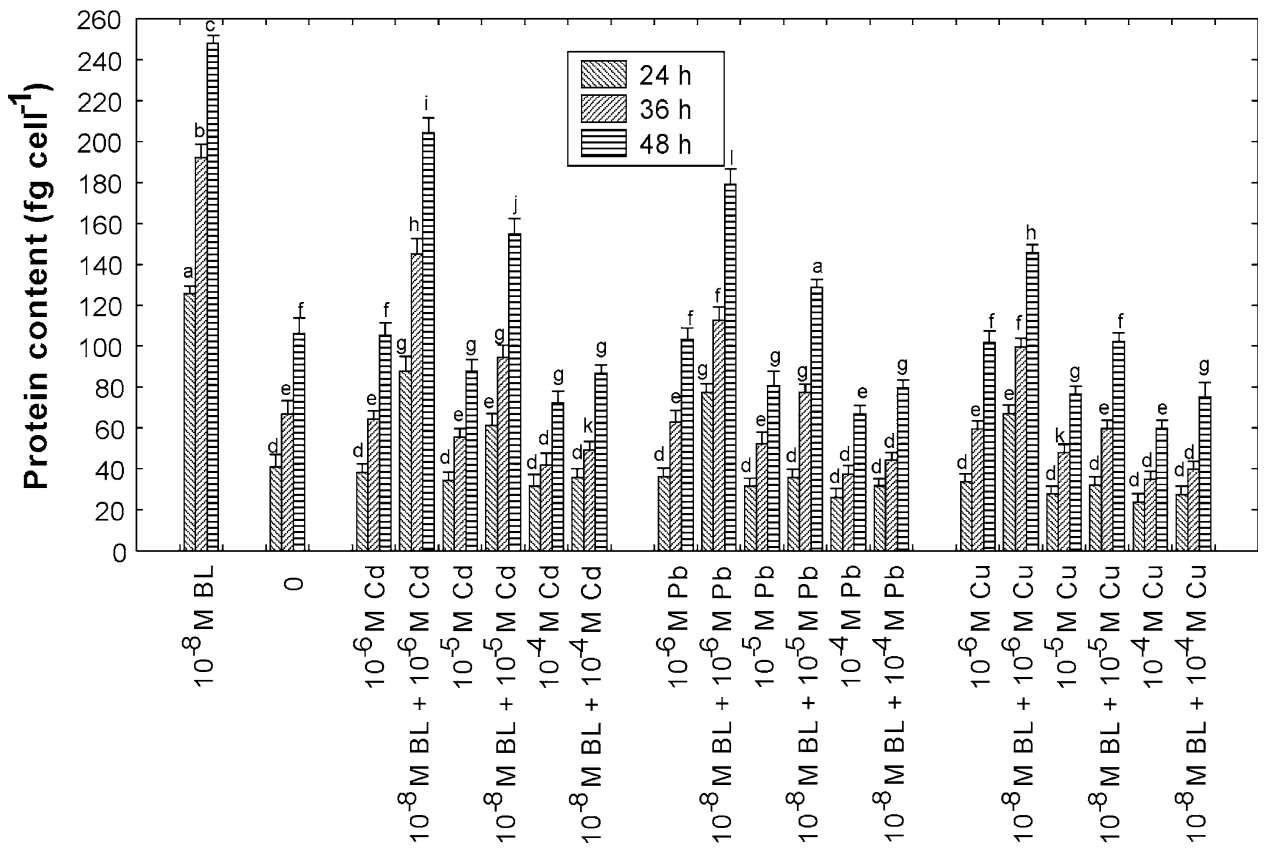

without any problems of toxicity. It is an important biochemical function of algae in the shaping of proper ecological relationships and interactions between organisms in the aquatic environment. Increasing levels of heavy metals in the environment affect various physiological and biochemical processes in plants. It can cause adverse effects on cell division, growth, photosynthesis, respiration, and degeneration of the main cell organelles (Wang and Chen 2009). Plants respond to heavy metal toxicity in different ways, such as the synthesis of phytochelatins, upregulation of antioxidants, accumulation of compatible solutes accumulation of low-molecular-weight metabolites, and changes in phytohormone levels (ABA, auxins, cytokinins, and gibberellins). One of the signal molecules that integrated the regulation of stress response and plant development are plant hormones: BRs (Bajguz and Hayat 2009).

The green alga $C$. vulgaris accumulated heavy metals $(\mathrm{Cd}, \mathrm{Pb}$, and $\mathrm{Cu})$ in a dose- and exposure-dependent manner. Heavy metals at the concentrations of $10^{-3} \mathrm{M}$, alone or mixed with $\mathrm{BL}$, showed a lethal effect on C. vulgaris (Bajguz 2000). At metal concentrations of $10^{-6}-10^{-4} \mathrm{M}$, a combination with $\mathrm{BL}$ appeared to have a 
Fig. 6 Effect of heavy metals $(\mathrm{Cd}, \mathrm{Pb}$, and $\mathrm{Cu})$ in the absence or presence of $\mathrm{BL}$ on the total PCs content in C. vulgaris cultures. Data are means $\pm \mathrm{SE}$ $(n=15)$. Before treatment of C. vulgaris cultures, the total PCs content was established at zero. Treatments with the same letter are not significantly different according to Duncan's test

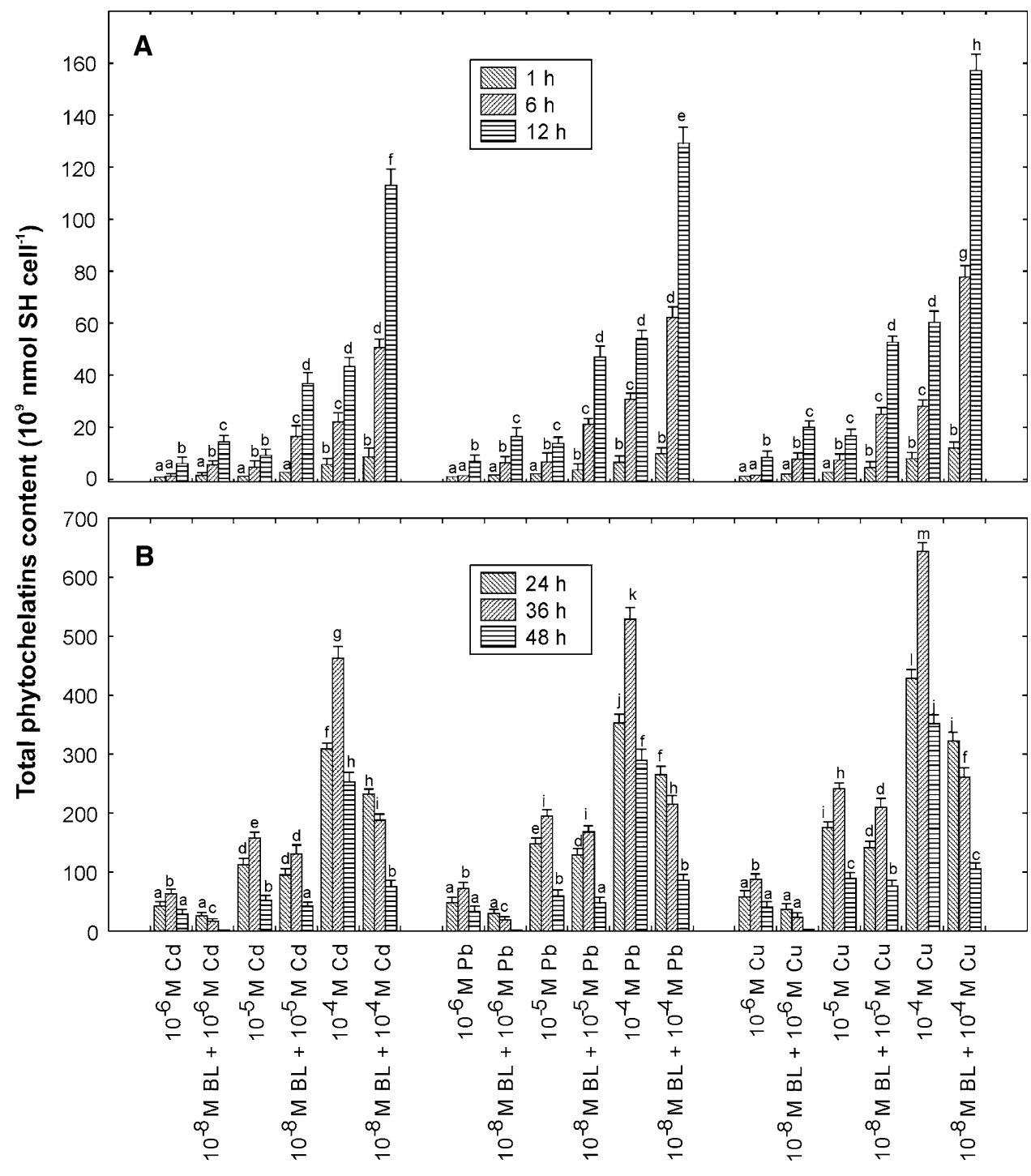

stronger stimulatory effect on the number of cells than a single metal (a stronger inhibitory effect). BL at the concentration of $10^{-8} \mathrm{M}$ in combination with heavy metals (in the range $10^{-6}-10^{-4} \mathrm{M}$ ) blocked their accumulation in the algal cells. A stimulatory effect of BL after blocking the accumulation of heavy metals on the growth of $C$. vulgaris occurs. The inhibitory effect of BL mixed with different heavy metals on their accumulation was arranged in the following order: $\mathrm{Zn}>\mathrm{Cd}>\mathrm{Pb}>\mathrm{Cu}$ (Bajguz 2000). This is in agreement with the earlier reports on aquatic plants such as C. vulgaris, Nasturtium officinale, Mentha aquatica, and Bacopa monnieri (Aslan et al. 2003; Bajguz and Godlewska-Żyłkiewicz 2004; Kessler 1986; Singh and Tewari 2003). $\mathrm{Cu}$ has been found to be one of more toxic metals to unicellular algae. Numerous comparative studies have reported the toxicity of $\mathrm{Cu}$ to the algal cells to be greater than that of $\mathrm{Cd}, \mathrm{Pb}$, chromium $(\mathrm{Cr})$, or $\mathrm{Zn}$ (Bilgrami and Kumar 1997; Ilangovan et al. 1992; Lam et al. 1999;
Macfie et al. 1994; Rachlin and Grosso 1993a, b). The accumulation of heavy metals under the influence of BRs has been studied for different agricultural plants such as barley, tomato, radish, and sugar beet. It was found that the application of 24-epiBL significantly reduced the metal absorption (Bajguz 2000). For example, the content of $\mathrm{Pb}$ in beet roots was more than $50 \%$ lower than in the control culture (Khripach et al. 1999).

Heavy metals exert toxic effects on the metabolic pathways of plants. Toxicity mechanisms include the blocking of functional groups of important molecules (e.g., enzymes, polynucleotides, transport systems for essential nutrients and ions, displacement and/or substitution of essential ions from cellular sites, denaturation and inactivation of enzymes, and disruption of cell and organellar membrane integrity). In addition, metals are also shown to exert toxic effects through free-radical formation. They are very toxic and oxidize biological macromolecules such as 
nucleic acids, proteins, and lipids, thereby disturbing the cell stability and membrane permeability. Heavy metals can elicit a variety of adaptive responses in plants. A ubiquitous mechanism for heavy metal detoxification is the chelation of the metal ion by ligands, such as organic acids, amino acids, and PCs, which play an important role in heavy metal homeostasis and detoxification. PCs are also considered as biomarkers of metal toxicity in higher plants (Cobbett 2000; Cobbett and Goldsbrough 2002; Rauser 1995)

Brassinosteroids stimulated the synthesis of PCs in C. vulgaris cells treated with $\mathrm{Pb}$ (Bajguz 2002). The stimulatory activity of BRs on PC synthesis was arranged in the following order: $\mathrm{BL}>24$-epiBL $>28$ homoBL $>$ castasterone $(\mathrm{CS})>24$-epiCS $>28$-homoCS. This study showed that the combination of BL and heavy metals had a greater amount of PC stimulation than heavy metals alone. The changes of PC content under the influence of BL with heavy metals take place at two stages. First, between the first and sixth hour of cultivation, the stimulation of PC is already observed, regardless of the concentrations of heavy metals or time of cultivation. At the 24th hour of cultivation, cultures of $C$. vulgaris treated with $\mathrm{BL}$ and heavy metals are characterized by the greatest stimulation of PC content. Second, from the 24th hour of cultivation, the stimulation of PC by heavy metals alone is more significant than with the interaction of BL.

Algae have been used to remove heavy metals from aquatic environment because they have a high capability to accumulate dissolved metals without dying (Sandau et al. 1996; Vílchez et al. 1997). Two types of mechanisms for the metal removal processes exist. First, passive uptake; it is called biosorption, which is metabolically independent. Biosorption is reversible and very rapid $(5-10 \mathrm{~min})$. The amount of metal accumulation per unit of biomass is proportional to the concentration of metal ion in the solution. In addition, biosorption can be affected by $\mathrm{pH}$ and the presence of other ions in the medium, which might precipitate heavy metal as insoluble salts, but it is unaffected by metabolic inhibitors or light/dark cycles. The toxicity of metals decreases with decreasing $\mathrm{pH}$ (Rachlin and Grosso 1993a; Volesky 1990). Some authors have shown an increase in metal toxicity with decreasing $\mathrm{pH}$. Acidity or alkalinity of medium can, in turn, moderate the toxicity of heavy metals. Lower $\mathrm{pH}$ might increase the bioavailability of metal ions resulting in increased toxicity (Franklin et al. 2000). It is known that BR-induced growth stimulation depends at least partly on the decrease of $\mathrm{pH}$ in the wall space and thus on acid-induced wall loosening (Bajguz 2000; Bajguz and Czerpak 1996; Romani et al. 1983). Second, active uptake is metabolically dependent. It may involve metal ion consumption for algal growth and/or intracellular accumulation of heavy metals. In addition, heavy metals might be precipitated by excreted secondary metabolites. These processes are energy dependent and sensitive to different parameters (e.g., $\mathrm{pH}$, temperature, light, etc.). Active uptake is more effective than biosorption for low concentrations of heavy metals (below $1 \mathrm{ppm}$ ). Both mechanisms can work simultaneously in the algal cells. However, biosorption was the major uptake component in C. vulgaris (Vílchez et al. 1997; Wilde and Benemann 1993). The response of BRs to heavy metals action was very quick by the synthesis of PCs, and after purification of cells from metals, the stimulation of $C$. vulgaris growth was observed.

Application of BL to $C$. vulgaris cultures reduced the accumulation of heavy metals stress on growth, prevented chlorophyll, sugar, and protein loss, and increased PC synthesis. Heavy metals have been found to decrease the total chlorophyll and sugar content in plants. Heavy metals inhibit the biosynthesis of chlorophyll pigments and enzymes involved in this process (Poskuta et al. 1996; Takamura et al. 1989). As a visible symptom, the reduced chlorophyll content can be used to monitor the heavymetal-induced damage in C. vulgaris cultures. Based on available data, it can be assumed that heavy metals might inhibit chlorophyll synthesis by causing impaired uptake of essential elements for photosynthetic pigments such as $\mathrm{Mg}$, K, Ca, and Fe by plants (Burzyński 1987). Moreover, an enhancement of chlorophyll damage occurs in the plants growing in the presence of $\mathrm{Pb}$ ions due to increased chlorophyllase activity (Drążkiewicz 1994). The inhibition in photosynthetic pigment accumulation in response to heavy metal stress might be also a consequence of peroxidation of chloroplast membranes via the increased rate of reactive oxygen species production (Bajguz 2010). It has been reported that BRs enhanced the level of the antioxidant system (superoxide dismutase, catalase, peroxidase, glutathione reductase, and proline), under heavy metals stress conditions. The influence of BRs on the antioxidant system was more pronounced under a stress situation. This suggests that the elevated level of the antioxidant system, at least in part, increased the tolerance of plants to heavy metal stress and thus protected the photosynthetic machinery and the plant growth.

Sugars are building substances for a plant as well as a key source of energy necessary for inciting all the biochemical processes (Moustakas et al. 1994). The reduction in sugar content in $C$. vulgaris cultures treated with heavy metals might be due to the enhancement in degradation of photosynthetic pigments contributing to the decline in photosynthesis and sugar accumulation. The protein content in C. vulgaris cultures decreased with the increase in heavy metal concentration for the 48-h treatment. Protein content, an important indicator of reversible and irreversible changes in metabolism, is known to respond to a wide variety of 
stressors (Singh and Tewari 2003). The inability of $C$. vulgaris cultures to accumulate proteins after heavy metals application might be caused by acute oxidative stress induced by heavy metals excess in plant cells. However, the decreased content of chlorophyll, sugar, and protein in C. vulgaris cells treated with heavy metals was restored by the coapplication of BL. Treatment of heavy metals and ecdysteroids manifested similar results by the increase of the content of chlorophyll, sugar, and protein in C. vulgaris (Bajguz and Godlewska-Żyłkiewicz 2004). However, BRs act more rapidly and the response is more intense than ecdysteroids. BRs exhibit structural similarities with ecdysteroids in that they both contain the entire cholesterol skeleton with the complete side chain. It leads to striking differences between the spatial shape of both types of steroid molecules and certainly might determine their biological properties.

One of the ways to obtain valuable information about the effect of heavy metals is the quantitative determination of the endogenous level of plant hormones. C. vulgaris has not yet been examined for its BRs content under heavy metals stress. Furthermore, there is a little information on the content of BRs in plants in response to this kind of stress. In C. vulgaris cultures treated with heavy metals, the endogenous level of $\mathrm{BL}$ was very similar to that of control. These results suggest that the activation of BRs biosynthesis, via an increase of endogenous BL, is not essential for the growth and development of $C$. vulgaris cultures in response to heavy metals stress. BRs are not involved by synthesizing de novo in response of algal growth under heavy metals stress but might interact via increasing the contents of other plant hormones (e.g., auxin, zeatin, and ABA).

Choudhary et al. (2009) showed that coapplication of 24-epiBL and $\mathrm{Cu}$ to Raphanus sativus seedlings resulted in the reduction of putrescine and spermidine contents. However, $\mathrm{Cu}$ treatment increased levels of polyamines when compared to control seedlings. A 24-epiBL treatment alone decreased levels of spermidine. Supplementation of metal treatment with 24-epiBL further recorded a decrease in free and bound IAA. Free and bound IAA showed maximum increase in 24-epiBL treatment alone, whereas maximum naphthalene acetic acid (NAA) levels (free and bound) were recorded in metal-treated seedlings only. In controls and 24-epiBL-treated seedlings, free and bound NAA was not detected. Moreover, a decrease in both forms of NAA was recorded in seedlings given treatments of $\mathrm{Cu}$ metal and 24-epiBL combinations. Enhanced contents of free and bound forms of NAA under metal treatment might suggest its effectiveness in oxidative stress management rather than IAA. Results of this study suggest significant effects of 24-epiBL on endogenous contents of polyamines and auxins under heavy metal stress, thereby indicating the modulation of stress management by BRs via regulating the contents of polyamines and auxins.
It was also reported that $\mathrm{Pb}$ increased $\mathrm{ABA}$ and cytokinins level an decreased the $\mathrm{GA}_{3}$ level in germinating chickpea seeds. On the other hand, high concentrations of $\mathrm{Zn}$ decreased the content of cytokinins and $\mathrm{GA}_{3}$, whereas low concentrations increased the content of these hormones (Atici et al. 2005; Hsu and Kao 2003; Sharma and Kumar 2002).

Open Access This article is distributed under the terms of the Creative Commons Attribution Noncommercial License which permits any noncommercial use, distribution, and reproduction in any medium, provided the original author(s) and source are credited.

\section{References}

Aslan M, Unlü MY, Türkmen N, Yilmaz YZ (2003) Sorption of cadmium and effects on growth, protein content, and photosynthetic pigment composition of Nasturtium officinale $\mathrm{R}$. Br. and Mentha aquatica L. Bull Environ Contam Toxicol 71:323-329

Atici Ö, Ağar G, Battal P (2005) Changes in phytohormone contents in chickpea seeds germinating under lead or zinc stress. Biol Plant 49:215-222

Bajguz A (2000) Blockade of heavy metals accumulation in Chlorella vulgaris cells by 24-epibrassinolide. Plant Physiol Biochem 38:797-801

Bajguz A (2002) Brassinosteroids and lead as stimulators of phytochelatins synthesis in Chlorella vulgaris. J Plant Physiol 159:321-324

Bajguz A (2009a) Brassinosteroid enhanced the level of abscisic acid in Chlorella vulgaris subjected to short-term stress. J Plant Physiol 166:882-886

Bajguz A (2009b) Isolation and characterization of brassinosteroids from algal cultures of Chlorella vulgaris Beijerinck (Trebouxiophyceae). J Plant Physiol 166:1946-1949

Bajguz A (2010) An enhancing effect of exogenous brassinolide on the growth and antioxidant activity in Chlorella vulgaris cultures under heavy metals stress. Environ Exp Bot 68:175-179

Bajguz A, Czerpak R (1996) Effect of brassinosteroids on growth and proton extrusion in the alga Chlorella vulgaris Beijerinck (Chlorophyceae). J Plant Growth Regul 15:153-156

Bajguz A, Godlewska-Żyłkiewicz B (2004) Protective role of 20-hydroxyecdysone against lead stress in Chlorella vulgaris cultures. Phytochemistry 65:711-720

Bajguz A, Hayat S (2009) Effects of brassinosteroids on the plant responses to environmental stresses. Plant Physiol Biochem 47:1-8

Bilgrami KS, Kumar S (1997) Effects of copper, lead and zinc on phytoplankton growth. Biol Plant 39:315-317

Bradford MM (1976) A rapid and sensitive method for the quantitation of microgram quantities of protein utilizing the principle of protein-dye binding. Anal Biochem 72:248-254

Burzyński M (1987) The influence of lead and cadmium on the absorption and distribution of potassium, calcium, magnesium and iron in cucumber seedlings. Acta Physiol Plant 9:229-238

Choudhary SP, Bhardwaj R, Gupta BD, Dutt P, Kanwar M, Arora M (2009) Epibrassinolide regulated synthesis of polyamines and auxins in Raphanus sativus $\mathrm{L}$. seedlings under $\mathrm{Cu}$ metal stress. Braz J Plant Physiol 21:25-32

Cobbett C (2000) Phytochelatins and their roles in heavy metal detoxification. Plant Physiol 123:825-832

Cobbett C, Goldsbrough P (2002) Phytochelatins and metallothioneins: roles in heavy metal detoxification and homeostasis. Annu Rev Plant Biol 53:159-182

Drążkiewicz M (1994) Chorophyll: occurrence, functions, mechanism of action, effects of internal and external factors. Photosynthetica 30:321-331 
Fahmi H, Shehata A, Whitton BA (1982) Zinc tolerance in strains of the blue-green alga Anacystis nidulans. Br Phycol J 17:5-12

Foster PL (1982) Metal resistance of Chlorophyta from rivers polluted by heavy metals. Freshwater Biol 12:1-61

Franklin NM, Stauber JL, Markich SJ, Lim RP (2000) pH-dependent toxicity of copper and uranium to a tropical freshwater alga (Chlorella sp.). Aquat Toxicol 48:275-289

Gupta M, Chandra P (1994) Lead accumulation and toxicity in Vallisneria spiralis and Hydrilla verticillata (L.) Royle. J Environ Sci Health A 29:503-516

Harding JPC, Whitton BA (1976) Resistance to zinc of Stigeoclonium tenue in the field and the laboratory. Br Phycol J 11:417-426

Hayat S, Ahmad A (eds) (2003) Brassinosteroids: bioactivity and crop productivity. Kluwer Academic, Dordrecht

Hsu YT, Kao CH (2003) Role of abscisic acid in cadmium tolerance of rice (Oryza sativa L.) seedlings. Plant Cell Environ 26:867-874

Ilangovan K, Salazar M, Dash S, Monroy O, Ramos A (1992) Interaction of cadmium, copper and zinc in Chlorella pyrenoidosa Chick. Environ Technol 13:195-199

Kessler E (1986) Limits of growth of five Chlorella species in the presence of toxic heavy metals. Arch Hydrobiol 73:123-128

Khripach VA, Zhabinskii VN, de Groot AE (1999) Brassinosteroids. A new class of plant hormones, Academic Press, San Diego

Lam PKS, Wut PF, Chan ACW, Wu RSS (1999) Individual and combined effects of cadmium and copper on the growth response of Chlorella vulgaris. Environ Toxicol 14:347-353

Macfie SM, Tarmohamed Y, Welbourn PM (1994) Effects of cadmium, cobalt, copper and nickel on growth of the green alga Chlamydomonas reinhardtii: the influence of the cell wall and pH. Arch Environ Contam Toxicol 27:454-458

Moustakas M, Lanaras T, Symeonidis L, Kartaglis S (1994) Growth and some photosynthetic characteristics of field grown Avena sativa under copper and lead stress. Photosynthetica 30:389-396

Pirson A, Lorenzen H (1966) Synchronized dividing algae. Annu Rev Plant Physiol 17:439-458

Poskuta JW, Parys E, Romanowska E (1996) Toxicity of lead to photosynthesis, accumulation of chlorophyll, respiration and growth of Chlorella pyrenoidosa. Protective role of dark respiration. Acta Physiol Plant 18:165-171

Prasad MNV (ed) (2004) Heavy metal stress in plants: from biomolecules to ecosystems. Springer-Verlag, Berlin

Rachlin JW, Grosso A (1993a) The growth response of the green alga, Chlorella vulgaris to combined divalent cation exposure. Arch Environ Contam Toxicol 24:16-20
Rachlin JW, Grosso A (1993b) The growth response of the green alga, Chlorella vulgaris to combined divalent cation exposure. Arch Environ Contam Toxicol 24:16-20

Rauser WE (1995) Phytochelatins and related peptides: structure, biosynthesis and function. Plant Physiol 109:1141-1149

Romani G, Marre MT, Bonetti A, Cerana R, Lado P, Marre E (1983) Effects of a brassinosteroid on growth and electrogenic proton extrusion in maize segments. Physiol Plant 59:528-532

Sandau E, Sandau P, Pulz O (1996) Heavy metal sorption by microalgae. Acta Biotechnol 16:227-235

Sayegh A, Greppin H (1973) Chlorella rubescens Ch. Essai de synchronisation et mise en évidence de rythmes endogènes. Arch Sci Genève 8:6-18

Sharma SS, Kumar V (2002) Responses of wild type and abscisic acid mutants of Arabidopsis thaliana to cadmium. J Plant Physiol 159:1323-1327

Singh VP, Tewari RK (2003) Cadmium toxicity induced changes in plant water relations and oxidative metabolism of Brassica juncea L. plants. J Environ Biol 24:107-112

Smirnoff N (ed) (1995) Environment and plant metabolism: flexibility and acclimation. BIOS Scientific, Oxford

Somogyi M (1954) Notes on sugar determination. J Biol Chem 195:19-23

Takamura N, Kusai F, Watanabe M (1989) Effects of $\mathrm{Cu}, \mathrm{Cd}, \mathrm{Zn}$ on photosynthesis of freshwater benthic algae. J Appl Phycol 1:39-52

Tukendorf A, Rauser WE (1990) Changes in glutathione and phytochelatins in roots of maize seedlings exposed to cadmium. Plant Sci 70:155-166

Vílchez C, Garbayo I, Lobato MV, Vega JM (1997) Microalgaemediated chemicals production and wastes removal. Enzyme Microb Technol 20:562-572

Volesky B (ed) (1990) Biosorption of heavy metals. CRC Press, Boca Raton, FL

Vymazal J (1990) Toxicity and accumulation of lead with respect to algae and cyanobacteria: a review. Acta Hydrochim Hydrobiol 18:513-535

Wang J, Chen C (2009) Biosorbents for heavy metals removal and their future. Biotechnol Adv 27:195-226

Wellburn AR (1994) The spectral determination of chlorophylls $a$ and $b$, as well as total carotenoids, using various solvents with spectrophotometers of different resolution. J Plant Physiol 144:307-313

Wilde EW, Benemann JR (1993) Bioremoval of heavy metals by the use of microalgae. Biotechnol Adv 11:781-812 